\title{
Suitability of three different cereal grains for spawn development and their impact on the growth and yield of Macrocybe gigantea (Massee) Pegler \& Lod.
}

\author{
Sapna Devi* \\ Department of Botany, University of Jammu, Jammu-180006 (J\&K), India \\ Geeta Sumbali \\ Department of Botany, University of Jammu, Jammu-180006 (J\&K), India \\ ${ }^{*}$ Corresponding author. E-mail: vermaasapnaa@gmail.com
}

\author{
Article Info \\ https://doi.org/10.31018/ \\ jans.v13i1.2547 \\ Received: February 2, 2021 \\ Revised: March 1, 2021 \\ Accepted: March 5, 2021
}

\section{How to Cite}

Devi, S. and Sumbali, G. (2021). Suitability of three different cereal grains for spawn development and their impact on the growth and yield of Macrocybe gigantea (Massee) Pegler \& Lod. Journal of Applied and Natural Science, 13(1): 204 - 209. https://doi.org/10.31018/jans.v13i1.2547

\begin{abstract}
Mushroom cultivation is an economical biotechnological process for the conversion of various unused lignocellulosic wastes into protein rich food. The present study was conducted to assess the suitability of three different cereal grains viz., bajra (Pennisetum glaucum L.), wheat (Triticum aestivum L.) and maize (Zea mays L.) for spawn production of Macrocybe gigantea (Massee) Pegler \& Lod. and further its cultivation on two agrowastes (wheat straw and paddy straw) for assessing biological efficacy. It was observed that among the three cereal grains tested, bajra grains took significantly $(P<0.05)$ less time for spawn development. Moreover, a minimum period of spawn run (16.3 days), highest sporophore yield ( $343.6 \mathrm{~g} / 500 \mathrm{~g}$ of dry substrate) and biological efficiency (68.7\%) were also recorded from substrate bags inoculated with bajra grain spawn. These results suggest the use of bajra grain spawn for quick and successful cultivation of $M$. gigantea.
\end{abstract}

\section{INTRODUCTION}

Mushrooms have been appreciated across the world for their unique flavour and have been valued by mankind as a culinary wonder (Patel and Goyal, 2012). They have been consumed by man for their delicious taste and pleasing flavour and are the cheapest source of protein particularly for the vegetarians. Besides being rich source of proteins, mushrooms also contain fats, vitamins, crude fiber, carbohydrates and some essential minerals, which are the key factors for the normal functioning of the body (Sharma et al., 2017). They also contain certain important vitamins like thiamine, ascorbic acid, nicotinic acid, riboflavin, pantothenic acid and biotin. This low cost vegetable is not only packed with essential nutrients but also has the unique properties to fight many deadly diseases (Thakur and Singh, 2014). Cultivation of mushrooms is an eco-friendly activity, which represents unique exploitation of the microbial technology for the bioconversion of the unused lignocellulosic wastes into nutritious food. In India, cultivation of edible mushrooms started way back in 1961, but emphasis is more on the temperate mushroom, Agaricus bisporus. However, our country can excel in the mushroom industry only by cultivating and commercializing some of the tropical and subtropical mushrooms. One such edible mushroom of the tropical region is Macrocybe, which belongs to the Family Tricholomataceae of the Order Agaricales (Kirk et al., 2008). It is characterized by large fleshy sporophores, excellent shelf life, ability to grow at temperature above $30^{\circ} \mathrm{C}$, high biological efficiency and easiness in post-harvest handling. Macrocybe resembles another edible summer mushroom, Calocybe very much as both have conspicuous large, saprophytic sporophores but it differs from Calocybe as it lacks siderophilous granulation in the basidia and differs at DNA level (Razaq et al., 2016). Macrocybe has seven well recognised species widely distributed in the tropical regions of the world (Pegler et al., 1998). However, from India, only five wild species of Macrocybe viz., M. crassa, M. pachymeres, M. gigantea, M. lobayensis and $M$. titans have been reported so far and cultivation of only $M$. gigantea has been attempted (Mohanan, 2011; Pamitha, 2014; 
Kushwaha et al., 2016; Bharti, 2019).

Macrocybe gigantea is an edible tropical mushroom, which was reported for the first time from West Bengal (Pegler et al., 1998) where it is locally named as "Boro dhoodh chattu" (Dutta and Acharya, 2014). It is a new addition to the basket of cultivated mushrooms, which can be grown during summer months. It requires a temperature between $25-35^{\circ} \mathrm{C}$, the relative humidity of 70 $80 \%$ and light of $8-10$ hours for its growth. To date, very few investigations have been done to determine the suitability of different cereal grains for spawn production of $M$. gigantea and its utility in the production of early fruiting bodies (sporophores) on the locally available lignocellulosic agrowastes (Duong et al., 2017 ; Akhtar et al., 2018) . Therefore, the present investigation was conducted to examine the suitability of different grains for spawn development and their impact on the growth behaviour and yield of $M$. gigantea.

\section{MATERIALS AND METHODS}

\section{Procurement of mushroom strain}

Pure culture of $M$. gigantea was procured from Directorate of Mushroom Research (DMR), Solan, Himachal Pradesh and Sher-e-Kashmir University of Agricultural Sciences and Technology (SKUAST), Jammu. The strain used for fruiting ability was maintained on potato dextrose agar (PDA) and malt extract agar (MEA) medium at room temperature and subculturing was done regularly after three months to sustain their fruiting vigour.

\section{Preparation of spawn}

The spawn was prepared by using the method outlined by Munjal (1973). Grains of three different cereals viz., bajra (Pennisetum glaucum L.), wheat (Triticum aestivum L.) and maize (Zea mays L.) were collected from the local market, thoroughly washed and soaked in water for 5-6 hours. After that, the grains were boiled for 30 minutes, drained, air-dried and mixed with 2 percent gypsum (calcium sulphate) and $0.5 \%$ chalk powder (calcium carbonate) to maintain $\mathrm{pH}$ at 6-7 and keep the grains separate from each other. After proper mixing, the grains were put in thoroughly cleaned bottles (500 $\mathrm{ml}$ ) and fresh polypropylene bags up to $3 / 4^{\text {th }}$ of their capacity, plugged with non-absorbant cotton and autoclaved at $15 \mathrm{lb} / \mathrm{sq}$. inch for 2 hours. After cooling, the sterilized grains were inoculated with 3-5 uniform sized mycelium discs of $M$. gigantea and incubated at $28 \pm 2^{\circ} \mathrm{C}$ till the mycelium covered the surface of the grains completely. Downward linear growth of the mycelium started in each bottle/bag within 3-4 days, which completely covered the grains within 15-20 days (Fig. 1).

\section{Collection and preparation of substrates}

Agricultural wastes like wheat straw ( $T$. aestivum L.) and paddy straw (Oryza sativa L.) were collected from the local fields of Jammu (India) and chopped into 5-7 $\mathrm{cm}$ pieces. Thereafter, they were subjected to hot water $\left(80-90^{\circ} \mathrm{C}\right)$ dip treatment in a drum for $40-50$ minutes. Excess water was drained off and the agrowastes were allowed to cool at room temperature and dry till $60 \%$ moisture was left. Substrates that on squeezing did not leak out drops of water were considered saturated with approximately $60 \%$ moisture level and were considered ready for use.

\section{Spawning and spawn run}

For the process of spawning, transparent polythene bags $(9 \times 16$ inch size) were taken and filled up to $3 / 4$ th of their capacity with alternate layers of the pasteurized substrate and spawn (5\%). The spawned bags were then transferred to hanging nets kept in the mushroom house. A temperature of $25-35^{\circ} \mathrm{C}$ and relative humidity of $80-90 \%$ was maintained in the mushroom house for spawn run. Each treatment was performed three times.

\section{Casing of bags}

After completion of the spawn run, the bags were opened and encased with 2-4 cm thick layer of farm yard manure (FYM), sterilized in an autoclave at $15 \mathrm{lbs}$ psi for 60 minutes. Casing layer was kept moist by sprinkling water as and when required.

\section{Cropping and harvesting}

After casing, the bags were retained in the hanging nets. After a few days, the mycelium of $M$. gigantea sprouted in the form of needle shaped primordia, some of which matured into large sporophores (Fig. 2). The sporophores on maturation were harvested by twisting lightly. The sporophore count and its corresponding weight were measured after every harvest.

\section{Biological efficiency (B . E)}

It is an estimate of the ability of mushrooms to convert substrate into fruiting bodies. It was calculated as per the following formula:

$$
\text { B.E }=\frac{\text { Fresh weight of mushroom yield }}{\text { Dry weight of substrate used }} \times 100 \quad \ldots . . . \text { Eq.1 }
$$

\section{Statistical analysis}

Data were subjected to Analysis of Variance (ANOVA) and the least significant difference was determined at the $5 \%$ level by Duncan Post Hoc test using SPSS software package (Srikram and Supapvanich, 2016).

\section{RESULTS AND DISCUSSION}

During these studies, observations were made on various aspects like spawn development, growth behaviour, pinhead number, sporophore number, yield potential and biological efficiency of $M$. gigantea cultivated on 

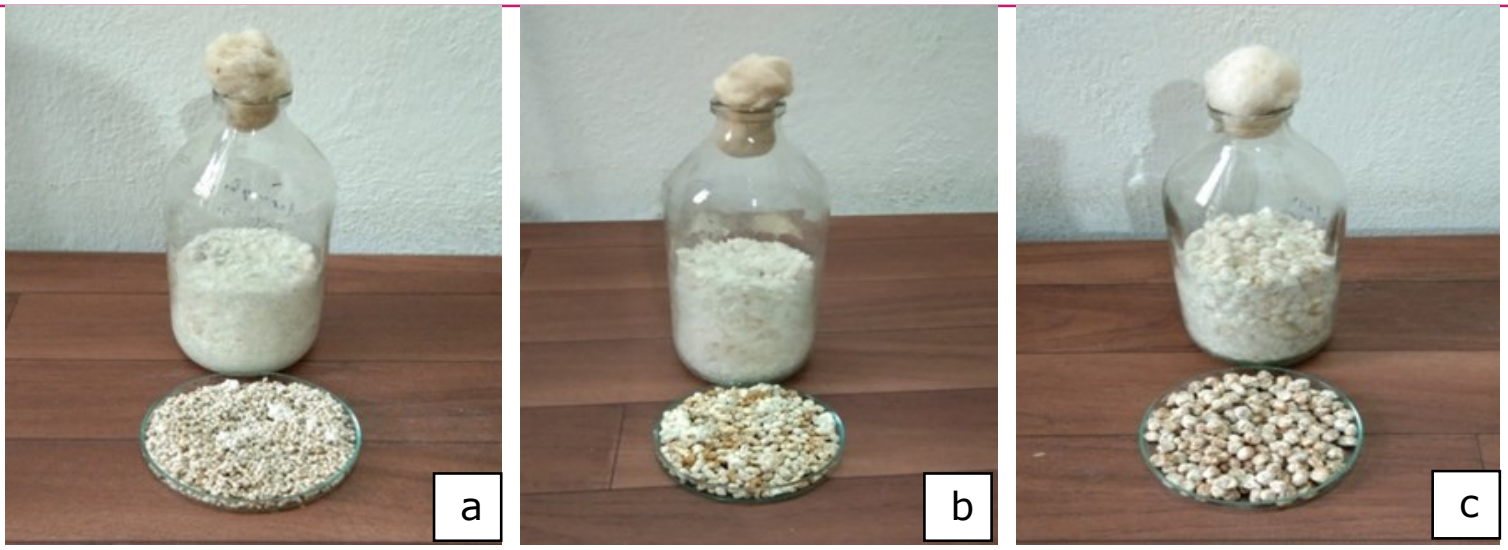

Fig. 1. Spawn prepared on: a. Bajra grains; b. Wheat grains; c. Maize grains.
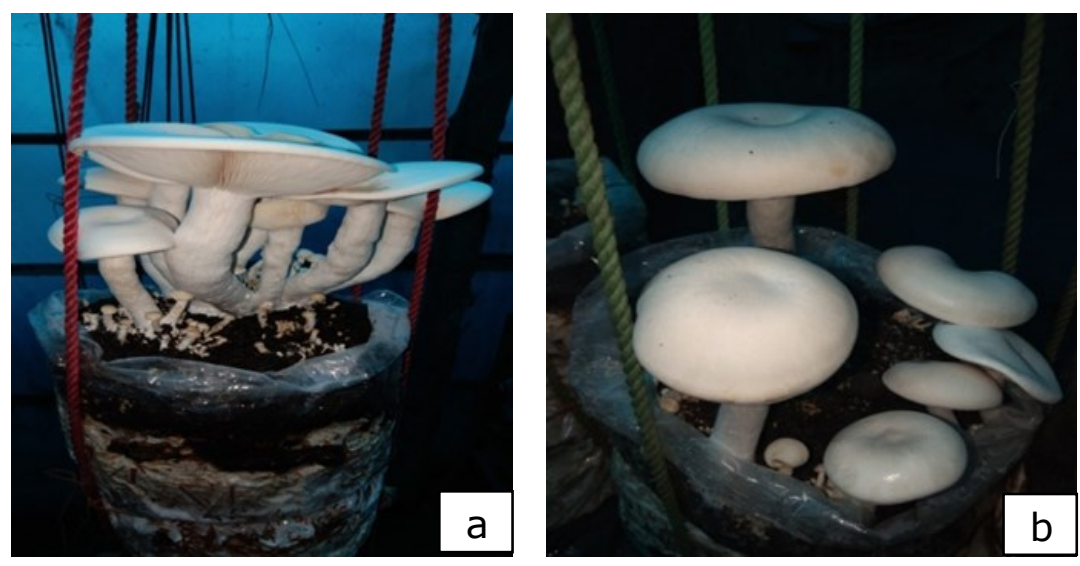

Fig. 2. Sporophores of M. gigantea cultivated on: a. Wheat straw; b. Paddy straw.

wheat straw and paddy straw waste.

\section{Assessment of duration required for spawn development of $M$. gigantea on different cereal grains}

Results depicted in Fig. 3 showed that minimum time for spawn preparation was recorded on bajra grains (14.3 days) followed by wheat grains (17.6 days), whereas maximum time was taken by maize grains (20.3 days). Variation in the time period required for spawn preparation may be attributed to the size of the grains. During the present investigation, the small sized grains of bajra get quickly enveloped with the mushroom mycelium than the larger grains of wheat and maize. Other workers have used wheat grains (Akhtar et al., 2018; Bharti, 2019), maize grains (Akhtar et al., 2018) and paddy grains (Pamitha, 2014 ; Duong et al., 2017) for spawn preparation of $M$. gigantea and have reported requirement of 15 to 25 days for its preparation. However, in view of the present observation, bajra grains are recommended for spawn preparation as it will affect the total duration required for the production of first flush of $M$. gigantea sporophores.

\section{Assessment of growth behaviour}

During the study, duration required for complete spawn run, pinhead formation and sporophore maturity of $M$. gigantea on two agrowastes (wheat straw and paddy straw) inoculated with three different grain spawns were assessed.

As depicted in Table 1, minimum period for spawn run (16.3 days) was recorded on wheat straw inoculated with bajra grain spawn. It was further observed that on paddy straw, all the three types of spawns made on bajra, wheat and maize grains showed non-significant differences in spawn run and took more time (up to 20.3 days). Earlier, few other researchers have also used wheat grain based spawn and they reported complete spawn run of $M$. gigantea on different agrowastes within 15-21 days of spawning (Kushwaha et al., 2016 ; Bharti 2019).

Statistical analysis of the data presented in Table 1 revealed that emergence of primordia took place equally well on wheat and paddy straw inoculated with bajra, wheat and maize grain spawn. However, minimum period required for primordial emergence after farm yard manure (FYM) casing was recorded on the paddy straw inoculated with bajra grain spawn (14.6 days). Earlier, Kushwaha et al. (2016) and Bharti, (2019) have recorded the emergence of pinheads on the agrowastes within 16 to 21 days of the casing. In contrast to these findings, Akhtar et al. (2018) reported that pinhead initiation of Tricholoma giganteum (Syn. Macrocybe gigantea) on the wheat straw took place after 


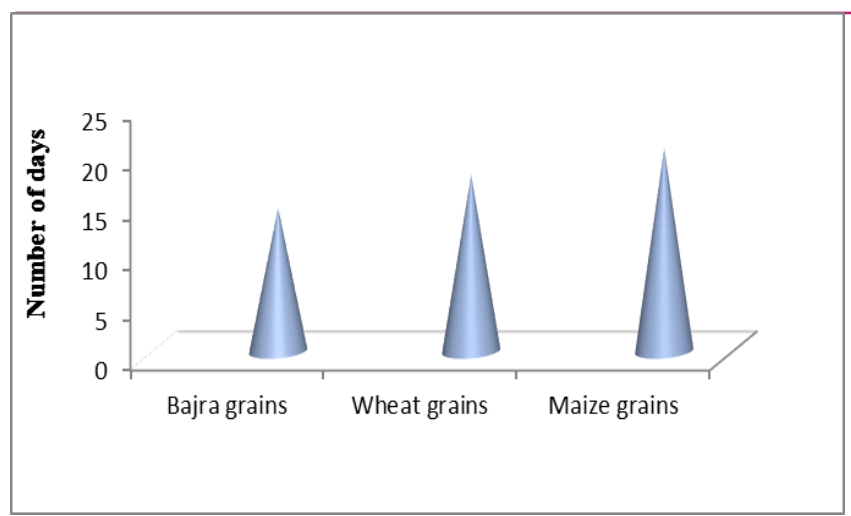

Fig. 3. Time period required for spawn preparation on different grains.

31-45 days of spawning by using wheat grain and maize grain based spawn.

Similarly, during the present investigation, nonsignificant differences were recorded with respect to the types of grain spawn used and the number of days required for obtaining mature sporophores (first flush). On the tested agrowastes inoculated with different spawns, minimum of 9.0 days and a maximum of 10.3 days were recorded for obtaining first flush after pinhead formation. However, in contrast to the present results, Bharti (2019) reported that by using wheat grain spawn, 13 to 17.87 days were required for the production of first flush of $M$. gigantea sporophores. Earlier, Duong et al. (2017) while cultivating another edible species of Macrocybe, $M$. titans by using paddy grain spawn found sporophores ready for harvesting within 7-10 days of pinhead formation.

\section{Assessment of pinhead and sporophore number}

Data presented in Table 2 showed non-significant differences with respect to number of pinheads on agrowastes spawned with three different types of spawn. Maximum (218.3) and minimum number (190.0) of pinheads were obtained on wheat straw inoculated with wheat grain spawn and bajra grain spawn respectively. The number of developing sporophores was also recorded as only few of the pinheads attained maturity. A perusal of data presented in Table 2 showed that paddy straw inoculated with bajra grain spawn proved to be the best as it resulted in the formation of the highest number of sporophores (20.6). This may be due to multilateral enzyme system of $M$. gigantea, which biodegrades a large range of lignocellulosic wastes (Kumla et al., 2020). The lowest number of sporophores (17.0) were recorded on wheat straw inoculated with maize grain spawn (Table 2). Statistically, differences were non-significant in term of sporophore number. Earlier, Kushwaha et al. (2016) recorded very high sporophore number of $M$. gigantea (54-110). However, Inyod et al.

Table 1. Time period (in days) required for the cultivation of M. gigantea on agrowastes inoculated with different grain spawns .

\begin{tabular}{|c|c|c|c|c|c|c|}
\hline \multirow{3}{*}{$\begin{array}{l}\text { Spawn pre- } \\
\text { pared on }\end{array}$} & \multicolumn{6}{|c|}{ Time period (in days) required for } \\
\hline & \multicolumn{2}{|c|}{ Spawn run } & \multicolumn{2}{|c|}{ Pinhead formation } & \multicolumn{2}{|c|}{ Production of first flush } \\
\hline & Wheat straw & Paddy straw & Wheat straw & Paddy straw & Wheat straw & Paddy straw \\
\hline Bajra grain & $16.3^{\mathrm{a}} \pm 0.66$ & $18.0^{\mathrm{a}} \pm 1.15$ & $16.3^{\mathrm{a}} \pm 0.66$ & $14.6^{a} \pm 0.88$ & $9.0^{\mathrm{a}} \pm 1.15$ & $10.3^{\mathrm{a}} \pm 0.88$ \\
\hline Wheat grain & $18.6^{\mathrm{b}} \pm 0.88$ & $20.0^{a} \pm 0.57$ & $18.3^{a} \pm 0.33$ & $15.0^{\mathrm{a}} \pm 1.00$ & $9.6^{a} \pm 0.33$ & $9.3^{a} \pm 0.88$ \\
\hline Maize grain & $19.3^{\mathrm{b}} \pm 0.33$ & $20.3^{a} \pm 1.20$ & $17.3^{\mathrm{a}} \pm 0.88$ & $14.0^{a} \pm 0.57$ & $9.0^{\mathrm{a}} \pm 0.57$ & $10.0^{\mathrm{a}} \pm 0.57$ \\
\hline F-value & 5.58 & 1.53 & 2.25 & 0.36 & 0.25 & 0.41 \\
\hline P-value & $P<0.05$ & $P>0.05$ & $P>0.05$ & $P>0.05$ & $P>0.05$ & $P>0.05$ \\
\hline
\end{tabular}

The values given are mean $(n=3) \pm$ standard error. Means followed by the same letter in the same column are not significantly different at $5 \%$ probability level according to the Duncan Post Hoc test.

Table 2. Pinhead and sporophore number of $M$. gigantea on agrowastes inoculated with different grain spawns.

\begin{tabular}{llllc}
\hline \multirow{2}{*}{ Spawn prepared on } & \multicolumn{2}{c}{ Pinhead number } & \multicolumn{2}{c}{ Sporophore number } \\
\cline { 2 - 5 } & Wheat straw & Paddy straw & Wheat straw & Paddy straw \\
\hline Bajra grain & $190.0^{\mathrm{b}} \pm 5.77$ & $212.6^{\mathrm{a}} \pm 3.71$ & $17.6^{\mathrm{a}} \pm 1.85$ & $20.6^{\mathrm{a}} \pm 2.84$ \\
Wheat grain & $218.3^{\mathrm{a}} \pm 7.21$ & $211.3^{\mathrm{a}} \pm 6.93$ & $20.3^{\mathrm{a}} \pm 2.72$ & $20.3^{\mathrm{a}} \pm 2.72$ \\
Maize grain & $203.0^{\mathrm{ab}} \pm 6.11$ & $217.3^{\mathrm{a}} \pm 1.76$ & $17.0^{\mathrm{a}} \pm 1.52$ & $18.0^{\mathrm{a}} \pm 1.52$ \\
F-value & 4.91 & 0.45 & 0.70 & 0.35 \\
P-value & $\mathrm{P}>0.05$ & $\mathrm{P}>0.05$ & $\mathrm{P}>0.05$ & $\mathrm{P}>0.05$ \\
\hline
\end{tabular}

The values given are mean $(n=3) \pm$ standard error. Means followed by the same letter in the same column are not significantly different at $5 \%$ probability level according to the Duncan Post Hoc test. 
Devi, S. and Sumbali, G. / J. Appl. \& Nat. Sci. 13(1): 204 - 209 (2021)

Table 3. Sporophore yield $(\mathrm{g})$ and biological efficiency (\%) of $M$. gigantea on agrowastes inoculated with different grain spawns.

\begin{tabular}{lcccc}
\hline \multirow{2}{*}{$\begin{array}{l}\text { Spawn prepared } \\
\text { on }\end{array}$} & \multicolumn{2}{c}{ Sporophore yield $(\mathbf{g})$} & \multicolumn{2}{c}{ Biological efficiency (\%) } \\
Paddy straw & Wheat straw & Paddy straw \\
\hline Bajra grain & $331.3^{\mathrm{a}} \pm 3.93$ & $343.6^{\mathrm{a}} \pm 2.96$ & 66.26 & 68.7 \\
Wheat grain & $332.0^{\mathrm{a}} \pm 3.05$ & $327.0^{\mathrm{b}} \pm 1.52$ & 66.4 & 65.4 \\
Maize grain & $320.0^{\mathrm{a}} \pm 4.04$ & $334.6^{\mathrm{ab}} \pm 4.37$ & 64.0 & 66.9 \\
F-value & 3.39 & 6.90 & & \\
P-value & $\mathrm{P}>0.05$ & $\mathrm{P}<0.05$ & & \\
\hline
\end{tabular}

The values given are mean $(n=3) \pm$ standard error. Means followed by the same letter in the same column are not significantly different at $5 \%$ probability level according to the Duncan Post Hoc test.

(2016) recorded very few sporophores (4.35-5.75) of another species of Macrocybe, $M$. crassa that was cultivated on rubber tree sawdust.

\section{Assessment of sporophore yield and biological efficiency}

Data given in Table 3 revealed non-significant differences in the yield of $M$. gigantea on wheat straw inoculated with three different grain spawns. Maximum yield (343.6g/500g of dry substrate) was recorded on paddy straw spawned with bajra grain spawn, whereas minimum yield $(320.0 \mathrm{~g})$ was obtained on wheat straw spawned with maize grain spawn. These results indicated that the grains used for spawn production significantly affect the sporophore yield of $M$. gigantea.

Biological efficiency obtained on the agrowastes was in accordance with the sporophore yield, being maximum $(68.7 \%)$ on paddy straw and minimum on wheat straw (64.0). An increase in the biological efficiency of $M$. gigantea on paddy straw may be due to the appropriate nutrient content of the substrate, which affected the growth and formation of sporophores. Pamitha (2014), Kushwaha et al, (2016) and Bharti, (2019) have also reported similar range of yield and biological efficiency ( $724 \mathrm{~g} / 1000 \mathrm{~g}$ of dry substrate, $72.4 \% ; 4493.3 \mathrm{~g} / 6400 \mathrm{~g}$ of dry substrate, $70.1 \% ; 651.87 \mathrm{~g} / 1000 \mathrm{~g}$ of dry substrate, $65.1 \%$ respectively) of $M$. gigantea on different agrowastes.

\section{Conclusion}

It can be concluded from the present study that bajra grains $P$. glaucum L.) are better than wheat grains ( $T$. aestivum L.) and maize grains (Z. mays L.) for the spawn production of $M$. gigantea as it gets ready in minimum time period (14.3 days), shows quick run ( 16.3 days) on the agrowastes and produces maximum sporophores (20.6) within few days of casing with farm yard manure.

\section{ACKNOWLEDGEMENTS}

The authors are thankful to the Department of Botany (UGC-SAP DRS II), University of Jammu, Jammu for providing laboratory facilities during the period of research. The first author gratefully acknowledges the financial support from University Grants Commission, New Delhi.

\section{Conflict of interest}

The authors declare that they have no conflict of interest.

\section{REFERENCES}

1. Akhtar, N.S., Dayaram. and Kumar, C. (2018). Yield performance and economics of grain based spawn of Tricholoma giganteum. Current Journal of Applied Science and Technology, 31, 1-9.

2. Bharti, V. (2019). Standardisation of cultivation technology of new tropical mushroom Macrocybe gigantea (Massee) Pegler \& Lodge. Ph.D Thesis, Department of Plant Pathology, Sher-e-Kashmir University of Agricultural Sciences and Technology (SKUAST), Jammu.

3. Duong, P.N., Duy, V.D., Anh, N.T., Xuan, B.T.T. and Tham, L.X. (2017). Studying identification and cultivation of Macrocybe titans, a new record species for Vietnam collected in Cat Tien National Park, south of Vietnam. Tap chi Sinh hoc, 39, 172-181.

4. Inyod, T., Sassanarakit, S., Payapanon, A. and Keawsompong, S. (2016). Selection of Macrocybe crassa mushroom for commercial production. Agriculture and Natural Resources, 50, 186-191.

5. Kirk, P.M., Canon, P.F., Minter, D.W. and Stalpers, J.A. (2008). Ainsworth and Bisby's Dictionary of the Fungi. CABI, UK.

6. Kushwaha, K.P.S., Kushwaha, A. and Mishra, S.K (2016). Yield evaluation of Macrocybe gigantea (Massee) Pegler \& Lodge (giant mushroom) on locally available different agro-wastes. Advances in Life Sciences, 5, 11277-11278

7. Kumla, J., Suwannarach, N., Sujarit, K., Penkhrue, W. Kakumyan, P., Jatuwong, K., Vadthanarat, S. and Lumyong, S. (2020). Cultivation of mushrooms and their lignocellulolytic enzyme production through the utilization of agro-industrial waste. Molecules, 25, 2811. doi: 10.339 0/molecules25122811

8. Mohanan, C. (2011). Macrofungi of Kerala. Kerala Forest Research Institute, Hand Book 27, Kerala, India, 597pp.

9. Munjal, R.L. (1973). Production of quality spawn of Agaricus bisporus and Volvariella spp. Indian Journal of Mush- 
Devi, S. and Sumbali, G. / J. Appl. \& Nat. Sci. 13(1): 204 - 209 (2021)

rooms, 1, 1-4

10. Pamitha, N.S. (2014). Medicinal and nutriceutical potential of giant mushroom (Macrocybe gigantea (Massee) Peglar \& Lodge). M.Sc. thesis, Department of Plant Biotechnology, College of Agriculture, Vellayani

11. Patel, S. and Goyal, A. (2012). Recent developments in mushrooms as anti-cancer therapeutics: A review. Journal of Biotechnology, 2, 1-15

12. Pegler, D.N., Lodge, D.J. and Nakasone, K.K. (1998). The pantropical genus Macrocybe gen. nov. Mycologia, 90, 494-504.

13. Razaq, A., Nawaz, R. and Khalid, A.N. (2016). An Asian edible mushroom, Macrocybe gigantea: its distribution and ITS-rDNA based phylogeny. Mycosphere, 7, 525-530

14. Sharma, V.P., Annepu, S.K., Gautam, Y., Singh, M. and Kamal, S. (2017). Status of mushroom production in India. Mushroom Research 26 (2), 111-120

15. Srikram, S. and Supapvanich, S. (2016). Proximate compositions and bioactive compounds of edible wild and cultivated mushrooms from Northeast Thailand. Agricultural and Natural Resources, 50, 432-436

16. Thakur, M.P. and Singh, H.K. (2014). Advances in the cultivation technology of tropical mushrooms in India. JNKVV Research Journal, 4, 20-135 